\title{
ESTUDO E APLICAÇ̃̃O DE TRANSPORTE COLABORATIVO PARA CARGAS DE GRANDE VOLUME
}

\author{
Rui Carlos Botter * \\ Douglas Tacla \\ Celso Mitsuo Hino \\ Escola Politécnica \\ Universidade de São Paulo (USP) \\ São Paulo - SP \\ rcbotter@usp.br \\ * Corresponding author/autor para quem as correspondências devem ser encaminhadas \\ Recebido em 03/2004; aceito em 10/2005 após 1 revisão \\ Received March 2004; accepted October 2005 after one revision
}

\begin{abstract}
Resumo
Esta pesquisa objetiva realizar um estudo de "Transporte Colaborativo" para grandes volumes, especificamente para conjugação de cargas no transporte rodoviário. A proposta é desenvolver uma metodologia capaz de conciliar e flexibilizar as restrições impostas pelas janelas de tempo, de modo a interferir nos níveis hierárquicos de decisão, minimizando gastos em fretes e consolidando os conceitos de transporte colaborativo em uma aplicação real. No nível estratégico: contribuir no planejamento dos locais de armazenagem; no nível tático: determinar o momento e origem da retirada; e no nível operacional: tratar especificamente a execução da conjugação das cargas. A aplicação ocorre suportada por um banco de dados com 411.852 registros, utilizando modelagem matemática para um caso no agronegócio brasileiro. Os resultados obtidos são muito satisfatórios e projetarão redução no frete rodoviário da ordem de R $\$ 12,7$ milhões por ano, na base de dados coletada, se a metodologia aqui proposta for implantada em sua plenitude.
\end{abstract}

Palavras-chave: transporte rodoviário; colaboração; logística colaborativa.

\begin{abstract}
This research proposes to carry out a study of Collaboration Transportation of large volumes, especially for conjugation of cargoes in the trucking transportation. This work presents a capable methodology to reconcile the needs of the transport with the imposed time windows restraints, coming to help in those restraints to interfere in hierarchy the decision levels. The interface in the strategic level is to contribute in the planning time of storage; the tactical planning level is to determination of the time windows and origin; the operational level is the specific operation from the conjugation of the shipments. The available primary database for the application to this case possesses 411.852 that support the application study in using a mathematical model. The results obtained were very satisfactory. Those results project a freight reduction about $\mathrm{R} \$ 12,7$ million per year, in the database available, if the methodology will be totally established.
\end{abstract}

Keywords: road transportation; collaboration; collaborative logistic. 


\section{Introdução}

A "Logística Colaborativa" é tida por diversos autores como a fase atual da logística ou a "nova onda" (Industry Directions, The Next Wave of Supply Chain Advantage, 2000). O Transporte colaborativo é uma parte, talvez a mais importante, da Logística colaborativa e essa um aspecto importante na evolução do "Gerenciamento da Cadeia de Suprimento". Estas hipóteses e conclusões, apesar de ainda pouco formalizadas em literatura, têm sido amplamente colocadas em fóruns importantes como o CLM (Council of Logistics Management). $\mathrm{O}$ transporte colaborativo surge então, como uma oportunidade e necessidade natural nesse processo.

Operacionalmente o transporte colaborativo acontece com o aproveitamento ou compartilhamento do mesmo equipamento de transporte para um ciclo fechado de movimentação de cargas (Browning, 2001). É preciso juntar os participantes da mesma cadeia logística ou embarcadores que ofereçam cargas complementares, ou seja, cargas compatíveis com o equipamento de transporte disponível na rota complementar, gerando a carga de retorno. A questão que se apresenta é: como obter êxito nesta aplicação prática de forma metodológica?

O transporte colaborativo pode ser uma ferramenta importante para a obtenção deste objetivo, existe, porém, lacunas na literatura especializada para materialização desses conceitos; e essa pesquisa procura trazer uma contribuição nesse sentido.

O caso real abordado neste trabalho e a base de dados disponível oferecem uma ótima oportunidade para o desenvolvimento de uma metodologia capaz de contribuir para formatação e alternativas para implementações práticas para o transporte colaborativo e especificamente no agronegócio, por meio da conjugação de cargas de soja e fertilizantes.

O transporte da soja é realizado de forma absolutamente dissociado do transporte de fertilizantes, pelo menos sob o ponto de vista das empresas produtoras envolvidas. Se existe alguma sinergia entre o caminhão (ou vagão) que transporta soja e o caminhão (ou vagão) que transporta fertilizante, ela só acontece por iniciativa do transportador contratado para efetuar as operações, portanto em beneficio deste. Tecnicamente é possível realizar o transporte de soja e retornar com o mesmo veículo transportando fertilizante; quando isso acontece sem a gestão das empresas que detêm as cargas, não há sinergia ou colaboração organizada entre as empresas que desta forma não percebem ganho operacional extra, mas sim a condição normal de mercado que regula tarifas e demanda de caminhões. A logística dessas empresas tem foco e objetivos diferentes e estas operam de forma independente a movimentação de seus produtos; assim o transporte conjugado de sua carga não é prática normal ou operacionalmente simples.

Os avanços tecnológicos embarcados nos caminhões vêm melhorando o desempenho operacional dos caminhões, aqueles que possuem um pouco mais de condição econômica e discernimento conseguem obter custos variáveis mais baixos (Copyright Technology Futures, 2000 e Wiley, 1997), mas a falta de produtividade, tarifas inadequadas e pouca eficácia na prospecção e operacionalização da carga de retorno fazem dos custos fixos um problema de difícil solução nas condições atuais do mercado. O custo de capital e a produtividade são fatores de extrema motivação para o desenvolvimento dessa pesquisa. À medida que o veículo não perde tempo procurando carga de retorno, está engajado de forma sinérgica em ciclo de viagens, caracterizado o transporte colaborativo, a produtividade cresce, crescendo a redução dos custos total de transporte (Tacla, 1999). 
Assim o objetivo deste trabalho é apresentar uma metodologia de conjugação de cargas a granel de grandes volumes no transporte rodoviário, flexibilizando as janelas de tempo, com aplicação ao caso Soja/Fertilizante, buscando a redução com gastos na contratação de fretes. Esse trabalho por fim deverá buscar aplicar os conceitos de transporte colaborativo, apoiando e influindo nos níveis hierárquicos de decisão: estratégico; tático; e operacional.

\section{Revisão Bibliográfica}

\subsection{Transporte Colaborativo}

O "Transporte Colaborativo" foi instituído como conceito no ano de 2000, surgindo a partir de uma segmentação e estudo particular do "CPFR" (Collaboration planning, Forecasting, and Replenishment). O fórum gerador desses comitês é o "VICS" (Voluntary Inter-Industry Commerce Standards Association), entidade norte Americana que objetiva criar colaboração entre vendedores e compradores através de co-gerenciamento de processos e sistemas de informações. Como conceito primário e gerador do CTM, o CPFR tem os seguintes objetivos básicos: melhorar eficiências; aumentar vendas; reduzir custos fixos, e capital de giro; reduzir estoques na cadeia de suprimentos; aumentar a satisfação dos clientes. Na busca constante de minimizar estoques na cadeia de valor, com janelas de planejamento mais curtas, o transporte se tornou uma questão crítica no processo. A Gestão do Transporte Colaborativo é um processo independente, porém simultâneo ao CPFR, construída nas mesmas relações entre os compradores e vendedores, mas incorporando informações novas e etapas com os transportadores; estende a atuação do CPFR desde a confirmação do pedido, e continua na entrega do produto, inclui as transações comerciais com o transportador, como o pagamento desse. As oportunidades para colaboração entre os compradores, vendedores e transportadores ocorrem em três categorias principais: planejamento estratégico; previsão de demanda, re-suprimento; e execução física.

\subsection{Revisão da literatura para tópicos correlatos e de suporte ao tema}

Para o desenvolvimento desta pesquisa foi realizada ampla revisão bibliográfica sobre o tema "Transporte Colaborativo" e sobre as ferramentas matemáticas capazes de auxiliar na solução; as matérias de interesse foram agrupadas por semelhança no tratamento dos dados ou objetivos para favorecer a análise dos textos escolhidos na revisão e emprestar um caráter didático ao trabalho. A Tabela 1 traz um comparativo das matérias estudadas como encontradas na literatura e as necessidades da proposta desta pesquisa. $\mathrm{Na}$ seqüência apresenta-se uma sinopse sobre os temas revisados. 
Tabela 1 - Literatura X Proposta da Pesquisa.

\begin{tabular}{|l|l|l|}
\hline \multicolumn{1}{|c|}{ Tópico } & \multicolumn{1}{|c|}{ Literatura } & \multicolumn{1}{c|}{ Abordagem desta Pesquisa } \\
\hline $\begin{array}{l}\text { Problemas de } \\
\text { roteamento de } \\
\text { veículos }\end{array}$ & $\begin{array}{l}\text { A grande maioria dos textos traz casos de } \\
\text { coleta e entrega e/ou carga parcial. }\end{array}$ & $\begin{array}{l}\text { O objetivo é tratar cargas fechadas de } \\
\text { grandes volumes. }\end{array}$ \\
\hline $\begin{array}{l}\text { Planejamento } \\
\text { de frota }\end{array}$ & As abordagens buscam redução de frota. & $\begin{array}{l}\text { Busca da redução de custo por } \\
\text { contratação de fretes mais baixos no } \\
\text { mercado, eliminando intermediários. }\end{array}$ \\
\hline $\begin{array}{l}\text { Expedição e } \\
\text { designação de } \\
\text { frota em } \\
\text { tempo real }\end{array}$ & $\begin{array}{l}\text { A literatura atual é farta em casos de } \\
\text { contratação de transporte em tempo real } \\
\text { para aplicações urbanas, como } \\
\text { entregadores, cargas expressas, e } \\
\text { atendimento de pequenos consumidores } \\
\text { (Business to Consumer). }\end{array}$ & $\begin{array}{l}\text { O objetivo do trabalho com “tempo real" } \\
\text { através das características agronômicas da } \\
\text { região, visando a deslocar a frota para o } \\
\text { local certo no melhor momento (Business } \\
\text { to Business). }\end{array}$ \\
\hline $\begin{array}{l}\text { Transporte } \\
\text { com carga de } \\
\text { retorno }\end{array}$ & $\begin{array}{l}\text { Também aqui a abordagem é coleta e } \\
\text { entrega e/ou carga parcial; os casos de } \\
\text { sucesso normalmente apresentados visam } \\
\text { à otimização da cadeia de suprimentos na } \\
\text { relação cliente fornecedor. }\end{array}$ & $\begin{array}{l}\text { O objetivo é conjugar cargas fechadas de } \\
\text { grande volume, onde as movimentações } \\
\text { não se completam na mesma cadeia de } \\
\text { suprimentos, mas podem tornar-se } \\
\text { complementares em um ciclo logístico. }\end{array}$ \\
\hline
\end{tabular}

\subsubsection{Problemas de roteamento de veículos e transporte com carga de retorno}

Os autores que pesquisaram os problemas clássicos (como o "Problema de Transporte", e "Caixeiro Viajante"), e suas inúmeras variantes, sempre o fizeram através de uma abordagem "estática", mais modernamente os mesmos problemas são tratados com decisões em tempo real, ou seja, de forma "dinâmica", distinguindo-os em uma determinada classe de problemas, denominada de "Problemas de Transporte Dinâmico", esta classe inclui, por exemplo: Expedição e roteamento dinâmico; Gerenciamento dinâmico de frota; Controle de tráfico terrestre; e Controle de tráfico aéreo.

Tratando especificamente de expedição e roteamento dinâmico, a primeira divisão a ser identificada é quanto ao tipo de movimentação, isto é Carga parcial (LTL), sujeita à consolidação e normalmente para entregas a mais de um destino diferente, ou Carga completa (TL), em que o veículo é enviado para um único destino.

A questão que tem o maior interesse dos pesquisadores é o posicionamento do veículo, assim que termine a viagem, de modo a antecipar a próxima demanda, com isso gerar ganhos em produtividade, bem como buscar e qualidade e rapidez no atendimento aos clientes.

A literatura é farta na abordagem de problemas de LTL, e mais ainda nessa categoria para entregas urbanas. Esta categorização classifica-se como transporte tipo "coleta e entrega", em que ainda os problemas podem ser tipificados como "muitos para muitos", ou "um para muitos", no primeiro caso coletas em vários pontos para entrega em vários pontos, no segundo coleta em um ponto para entrega em vários pontos (que pode ser o inverso: "muitos para um"). Diversos casos podem servir como exemplos do colocado acima, como: carros para atendimento a emergências; courier; entregas rápidas pedidas por telefone; etc. Para todos eles a roteirização deverá ser dinâmica suficiente para que atenda rapidamente todo e qualquer pedido, feito via de regra por telefone diretamente do cliente requisitante, ao mesmo tempo otimizar o uso da frota existente buscando a otimização de sua carga. 


\subsubsection{Planejamento de frota e expedição e designação de frota em tempo real}

$\mathrm{O}$ problema de planejamento e designação de veículos às rotas, consiste em consolidar uma programação de viagens e a respectiva designação de veículos, que atenda ao conjunto de restrições correspondentes, ao mesmo tempo em que venha a otimizar a "função objetivo" do problema. Segundo Crainic (1998), o desafio na construção de controles operacionais em tempo real, para sistemas complexos, requer a participação de diferentes grupos de pessoas que contribuem de diferentes formas, como acontece em transporte.

$\mathrm{O}$ problema de designação tem um espectro amplo e não trata apenas de um problema específico de alocação simples, ou designação do veículo de transporte, mas pode estar relacionado a um número grande de possibilidades; sem a intenção de esgotá-las. Seguem-se alguns exemplos: $\mathrm{O}$ veículo (caminhão, navio, avião, etc.) a uma determinada rota; $\mathrm{O}$ veículo a um determinado cliente, ou a conjuntos de clientes; $\mathrm{O}$ veículo a uma determinada carga, ou a um conjunto de cargas; $\mathrm{O}$ veículo a um ponto de origem ou destino, como caminhões às garagens, navios aos portos, aviões aos aeroportos, etc.; Motoristas ao veículo, tripulações aos navios ou aviões. A literatura é farta nesse tópico, porém não para o planejamento e designação de veículos rodoviários de carga; encontra-se um número muito maior para frotas de navios, e ainda, referências para planejamento de frotas de aeronaves.

\section{Descrição do Estudo de Caso e Desenvolvimento de Heurística de Análise}

A base de dados real a ser aplicada no modelo, possui 411.852 (quatrocentos e onze mil, oitocentos e cinqüenta e dois) registros, perfazendo mais de 450.000 (quatrocentos e quarenta mil) viagens de soja e fertilizantes. As tabelas foram uniformizadas e todas as cidades receberam a classificação do IBGE (Instituto Brasileiro de Geografia e Estatística) para micro e mesorregião. Essa classificação permite agrupar as cidades em pequenos pólos agrícolas para expedição de soja ou recebimento de fertilizantes. A conta com frete terrestre computada aproxima-se de 10\% (dez por cento) do faturamento total das Empresas estudadas e que cederam os dados para a pesquisa, e em valores monetários alcança cifras da ordem de US\$250.000.000 (base 2002). As empresas são as maiores em seus respectivos segmentos no âmbito brasileiro e com projeção global.

Visando a proceder à análise da questão das janelas de tempo em que ocorrem as movimentações, o cenário foi dividido em quatro pólos geográficos buscando potencializar as possibilidades de sinergia logística e conjugação de cargas; para cada um dos pólos foram plotados os volumes, semana a semana, nas rotas escolhidas para ambos os produtos, e assim a heurística foi desenvolvida buscando conjugar as cargas realizadas em rotas cruzadas (entende-se por "rota cruzada" aquela em que o mesmo ponto geográfico é origem para um itinerário e o destino para o outro, encerrando um ciclo de rota principal e de retorno). Nas análises e tratamento dos dados foram utilizadas cidades para as origens, e mesorregiões para os destinos de fertilizante, e o inverso para soja. As janelas de tempo foram flexibilizadas em três dias (para frente ou para trás); a escolha da flexibilização de três dias foi decidida com base em aspecto puramente prático, já que tanto para embarque de soja e para entrega de fertilizante (produtos agrícolas em geral) os prazos são acordados em forma de janelas semanais, diferentemente do que ocorre com produtos de alto valor agregado.

A apuração dos resultados é obtida pela diferença da conta frete original, pela nova conta frete obtida com a conjugação de cargas. Os resultados mostram que a iniciativa da pesquisa é válida, as premissas foram legitimadas com mostras de reais possibilidades de ganhos; 
alcançando $54 \%$ de conjugação de cargas, ou mais de 212 mil toneladas, motivando assim a continuidade da pesquisa com uma proposta metodológica mais ampla.

A heurística elaborada nessa etapa não poderia ser utilizada na abrangência total da base de dados do caso real por utilizar meios incompatíveis com a magnitude dos problemas, e principalmente por não produzir solução ótima, daí então a seqüência da metodologia propor uma modelagem matemática fundamentada em pesquisa operacional. $\mathrm{O}$ modelo matemático vai tratar não só da conjugação de rotas permeando as janelas de tempo, como a que se propõe essa heurística, mas atuar nos níveis hierárquicos de decisão.

A Empresa que movimenta soja denomina-se A e a que movimenta Fertilizante B, como nomenclatura nesta pesquisa.

\section{Descrição da Metodologia para o Desenvolvimento dos Modelos Matemáticos para o Transporte Colaborativo}

A consolidação da Metodologia de Implementação dos conceitos de Transporte Colaborativo deverá estar faceada com os três níveis hierárquicos de decisão: estratégico, tático e operacional. Para cada um dos níveis a metodologia visa à obtenção do maior número de rotas conjugadas a fim de diminuir o custo na contratação de transporte. Mesmo os momentos e horizontes dos modelos serem diferentes, pois aplicam-se separadamente em cada um dos respectivos níveis, o processo é único e contínuo, obrigatoriamente interligado e interdependente. Pode-se assim estabelecer uma descrição preliminar da metodologia, com a visão geral do processo, descrição esta que acaba por completar-se com o Fluxograma correspondente.

4.1 Nível Estratégico: As empresas de forma independente e dissociada realizam seus respectivos planos de negócios (denominado BP para este trabalho - abreviatura para Business Plan). A partir desse plano macro, as áreas de planejamento logístico passam a criar um plano de armazenagem e transporte. Nesse ponto a metodologia propõe a completa interação dos planos individuais, criando já um plano integrado de movimentação, com proposição direta de seqüenciamento de movimentação de soja, visando favorecer no plano tático a conjugação de cargas. A colaboração então se dá já no planejamento logístico macro, com o posicionamento dos estoques, a seqüência de sua movimentação de soja, e locais e momentos de entrega de fertilizante. O horizonte é anual (alguns autores consideram o horizonte anual como curto para estratégico e o apropriam como "tático de longo prazo", como Yoshizaki, 1996), pois é coincidente com o período que ocorre o Planejamento de Negócio das empresas.

4.2 Nível Tático: Iniciando-se a operação propriamente dita, a partir de um planejamento mensal de movimentação de soja e fertilizante, a aplicação do modelo matemático será no nível tático. O resultado desta etapa da metodologia irá indicar as rotas possíveis de conjugação e aquelas rotas que poderão ser conjugadas no plano operacional, se e somente se houver a concordância do deslocamento das janelas de tempo de movimentação das rotas em questão de modo que essas sejam coincidentes. A colaboração nessa etapa atinge não só os níveis de planejamento operacional, mas também as áreas diretamente ligadas às áreas de negócio. A área de vendas de fertilizante deverá concordar em adiantar ou atrasar entregas a seus clientes. 
A flexibilização das janelas de tempo de entrega de fertilizante. É importante notar que se no nível estratégico a área de negócios e de logística da empresa de grãos deveria flexibilizar e mudar eventualmente a seqüência de movimentação dos silos de soja, agora é a área comercial de fertilizante que deverá flexibilizar e colaborar, já que a movimentação de soja estará em marcha, buscando normalmente um navio atracado para exportação, ou uma fábrica requerendo matéria prima. $\mathrm{O}$ volume de movimentação de fertilizante é menor e comercialmente o cliente (mediante a planejamento prévio e consulta) pode receber alguns dias antes ou depois; desta forma é o fertilizante que tem de buscar coincidir sua movimentação com a expedição de soja. Na prática o fertilizante é carga de retorno para a soja, e a flexibilização das janelas de entrega de fertilizante aumenta a possibilidade de conjugação de rotas.

4.3 Nível Operacional: A seqüência da metodologia irá fechar o processo propondo então um conjunto viável e maximizado de rotas conjugadas. O horizonte de planejamento é semanal e não cabe modelo matemático de programação linear; desta feita à metodologia propõe a programação direta de transporte: a carteira de pedidos de entrega de fertilizante e a necessidade consolidada de soja. A programação irá apresentar o conjunto de rotas conjugadas e aquelas de impossível conjugação, em ambos os casos a execução das viagens é ordenada. A Figura 1 ilustra em forma de fluxograma a metodologia proposta, para o caso Soja/Fertilizante escolhido para a aplicação.

4.4 Hipóteses assumidas para a implementação da Metodologia: Com o objetivo de tornar a metodologia genérica e aplicável para outros casos, admitem-se as hipóteses:

1. Transporte terrestre de grandes volumes de carga, em extensa abrangência geográfica e de rotas;

2. Cargas fechadas, completas, ponto a ponto;

3. Plano de Negócios com horizonte anual, como uma ferramenta de gestão no nível hierárquico estratégico (tático de longo prazo) de decisão

4. Plano de Transportes (rotas) com horizonte mensal, como uma ferramenta de gestão no nível hierárquico tático de decisão;

5. Conjugação de pares de viagens $(\mathrm{A}+\mathrm{B})$, não se conjuga mais de duas rotas diferentes;

6. Demandas conhecidas;

7. Capacidades de armazenamento finitas e conhecidas;

8. Capacidade ilimitada de transporte e os custos unitários não variam com o volume;

9. Rotas conjugadas têm custo (ou frete) $6 \%$ menor do que a soma das rotas simples correspondentes.

A metodologia apresentada poderia ser utilizada, respeitando-se as hipóteses apresentadas em vários outros casos, como Minério de ferro, produtos de aço, produtos derivados de petróleo envasados, Cimento, e uma série de outros produtos agrícolas. 


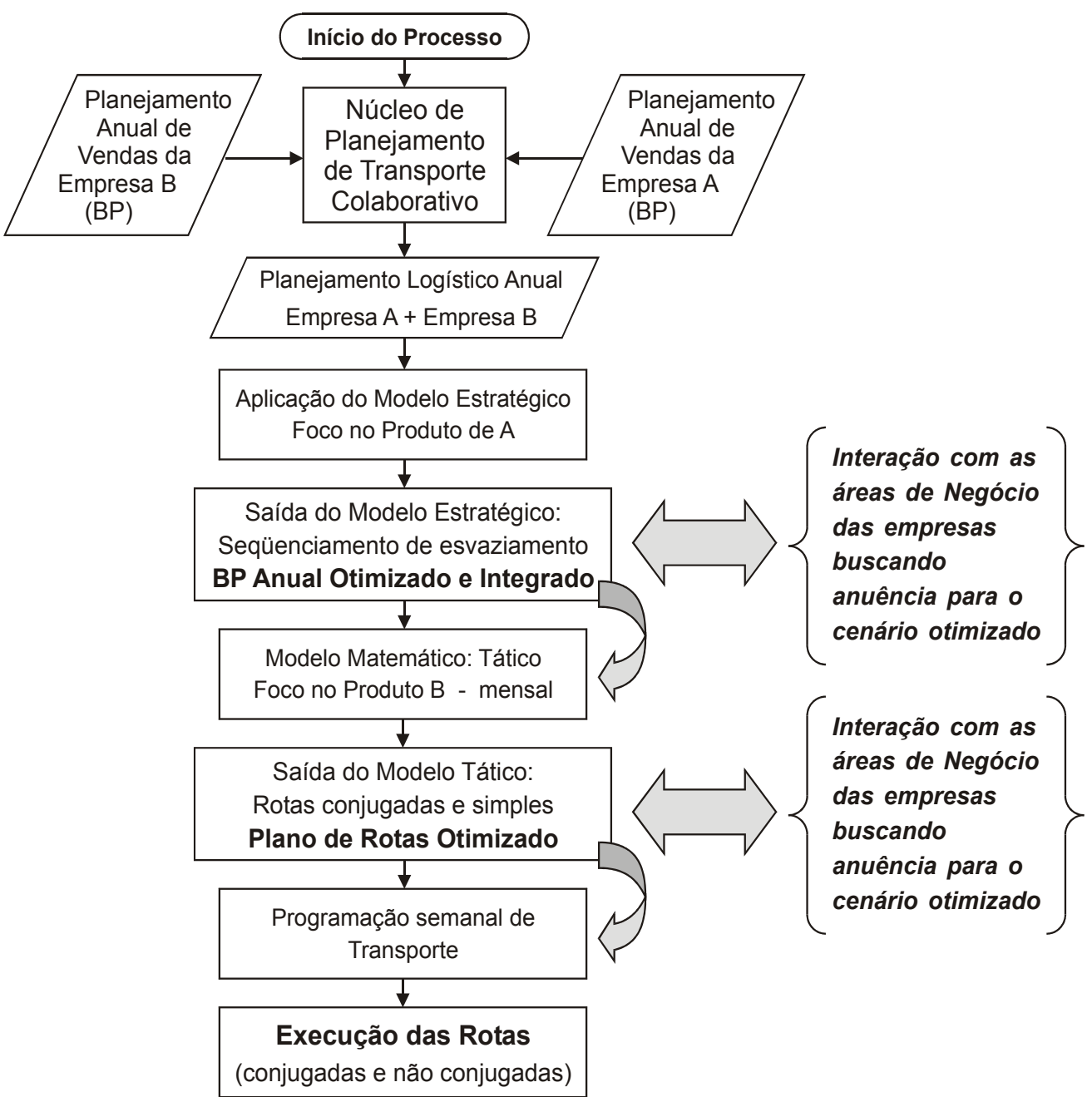

Figura 1 - Fluxograma com a descrição da metodologia proposta.

\section{Desenvolvimento da Modelagem Matemática e Aplicação ao Caso Real}

\subsection{Nível Estratégico}

As Variáveis de Decisão no Nível Estratégico são:

1. Rotas e Cargas com conjugação possível nos horizontes mensais de planejamento (enviada à interação no nível tático).

2. Propor Alternativas de re-planejamento para a movimentação dos estoques de A no tempo, sem inserir ou eliminar os pontos de armazenagem já existentes.

Entrada de Dados: resultado do BP, planejamento de negócio com foco logístico.

Horizonte de Programação: cinqüenta e duas semanas (um ano). 
Nomenclatura dos Índices

Os seguintes índices serão utilizados para o desenvolvimento do modelo matemático - foco estratégico neste trabalho:

i ... para pontos de origem da Empresa $\mathrm{A}$, associado também às instalações de armazenagem da empresa A;

$\checkmark \quad j$... para pontos de destino da Empresa A, associado também às instalações de processamento ou escoamento da Empresa A;

$\checkmark \quad m$... para pontos de origem da Empresa $\mathrm{B}$, associados também às instalações processadoras da empresa $\mathrm{B}$;

$\checkmark \quad n$... para pontos de destino da Empresa B, associados também aos clientes de Empresa B;

$\checkmark \quad t \ldots$ para indicar o período de tempo.

Relativo aos conjuntos de índices:

$\checkmark \quad I$... para indicar o conjunto de todos os pontos de origem da Empresa A;

$\checkmark \quad J \ldots$ para indicar o conjunto de todos os pontos de destino da Empresa A;

$\checkmark \quad M$... para indicar o conjunto de todos os pontos de origem da Empresa B;

$\checkmark \quad N$... para indicar o conjunto de todos os pontos de destino da Empresa B;

$\checkmark \quad T \ldots$ para indicar o conjunto com todos os períodos de tempo.

Parâmetros

Os parâmetros utilizados no modelo matemático - foco estratégico estão descritos a seguir:

Relativo aos custos:

$\checkmark C^{X}{ }_{i, j, t} \ldots$ custo do frete em $\mathrm{R} \$ /$ t. para a rota com origem de índice $i$ para o destino de índice $j$ no período de tempo de índice $t$;

$\checkmark C_{m, n, t}^{Y} \ldots$ custo do frete em $\mathrm{R} \$ / \mathrm{t}$. para a rota com origem de índice $m$ para o destino de índice $n$ no período de tempo de índice $t$;

$\checkmark C_{i, j, m, n, t}^{W A B}$ custo do frete em $\mathrm{R} \$ / \mathrm{t}$. para a rota conjugada com uma rota da Empresa A de origem de índice $i$ para o destino de índice $j$ seguido de outra rota da Empresa B de origem de índice $m$ para o destino de índice $n$ no período de tempo de índice $t$;

$\checkmark C_{m, n, i, j, t}^{W B}$.. custo do frete em $\mathrm{R} \$ /$ t. para a rota conjugada com uma rota da Empresa B de origem de índice $m$ para o destino de índice $n$ seguido de outra rota da Empresa A de origem de índice $i$ para o destino de índice $j$ no período de tempo de índice $t$.

Relativo às demandas e ao $B P$ :

$\checkmark D_{j, t}^{A} \ldots$ demanda das instalações de processamento ou escoamento da Empresa A (necessidade de alocação de soja) no ponto de índice $j$ no período de tempo de índice $t$;

$\checkmark D^{B}{ }_{n, t} \ldots$ demanda dos clientes da Empresa B (necessidade de alocação de fertilizante) no ponto de índice $n$ no período de tempo de índice $t$;

$\checkmark B_{i, j, t}^{A} \ldots B P$ da Empresa A para a rota de origem de índice $i$ para o destino de índice $j$ no período de tempo de índice $t$, este parâmetro reflete o resultado do BP da Empresa A no que tange ao planejamento anual de expedição (movimentação) de soja; 
$\checkmark B_{m, n, t}^{B} \ldots B P$ da Empresa B para a rota de origem de índice $m$ para o destino de índice $n$ no período de tempo de índice $t$ este parâmetro reflete o resultado do BP da Empresa B no que tange ao planejamento anual de entregas (movimentação) de fertilizante.

Relativo aos estoques:

$\checkmark \quad E_{i, t}^{A M} \ldots$ estoque mínimo a ser deixado no final do período de índice $t$ nas instalações de armazenagem no ponto de índice $i$;

$\checkmark E^{A X}{ }_{i, t} \ldots$ estoque máximo permitido na instalação de armazenagem no ponto de índice $i$ no período de índice $t$;

$\checkmark \quad E_{i, t}^{A B P} \ldots$ entrada de produtos estimada pelo $B P$ da Empresa A para as instalações de armazenagem no ponto de índice $i$ até o inicio do período de índice $t$;

$\checkmark \quad E^{I}{ }_{i} \ldots$ estoque inicial de produtos nas instalações de armazenagem da Empresa A no ponto de índice $i$.

Nota: Não há prática de mercado de estoques de Fertilizantes, são milhares de combinações de nutrientes e portanto, uma infinidade de possibilidades de produtos; a produção é do tipo "make to order" (produção mediante pedido).

Relativo aos fatores de flexibilização:

$\checkmark F_{i, j, t}^{A} \ldots$ fator de flexibilização do $B P$ da Empresa A para a rota de origem de índice $i$ para o destino de índice $j$ no período de tempo de índice $t$;

$\checkmark F_{m, n, t}^{B} \ldots$ fator de flexibilização do $B P$ da Empresa B para a rota de origem de índice $m$ para o destino de índice $n$ no período de tempo de índice $t$.

Os fatores de flexibilização variam entre zero e um, sendo o valor igual zero indicando nenhuma margem de flexibilização e valor um indicando capacidade total de replanejamento.

Variáveis de decisão

As seguintes variáveis de decisão compõem o modelo matemático proposto:

$\checkmark \quad X_{i, j, t} \ldots$ quantidade em toneladas transportada pela Empresa A da origem de índice $i$ para o destino de índice $j$ no período de tempo de índice $t$;

$\checkmark Y_{m, n, t} \ldots$ quantidade em toneladas transportada pela Empresa B da origem de índice $m$ para o destino de índice $n$ no período de tempo de índice $t$;

$\checkmark W_{i, j, m, n, t}^{A B} \ldots$ quantidade em toneladas transportada em rota conjugada com uma rota da Empresa A de origem de índice $i$ para o destino de índice $j$ seguido de outra rota da Empresa $\mathrm{B}$ de origem de índice $m$ para o destino de índice $n$ no período de tempo $t$;

$\checkmark W_{m, n, i, j, t}^{B A} \ldots$ quantidade em toneladas transportada em rota conjugada com uma rota da Empresa $\mathrm{B}$ de origem de índice $m$ para o destino de índice $n$ seguido de outra rota da Empresa A de origem de índice $i$ para o destino de índice $j$ no período de tempo $t$

$\checkmark E^{A}{ }_{i, t} \ldots$ estoque na instalação da Empresa A localizado na origem de índice $i$ no período de tempo de índice $t$;

$\checkmark C^{T} \ldots$ custo total em $\mathrm{R} \$$ das operações de frete da Empresa A e Empresa B. 
Função objetivo:

Função com objetivo de minimizar a conta frete de todo o sistema. Na inexistência das rotas conjugadas (variáveis $W$ ), minimizaria o custo da conta frete das duas empresas considerando uma operação totalmente estanque da outra:

$$
\begin{aligned}
& C^{T}=\sum_{i}^{I} \sum_{j}^{J} \sum_{t}^{T}\left(X_{i, j, t} \times C_{i, j, t}^{X}\right)+\sum_{m}^{M} \sum_{n}^{N} \sum_{t}^{T}\left(Y_{m, n, t} \times C_{m, n, t}^{Y}\right)+ \\
& +\sum_{i}^{I} \sum_{j}^{J} \sum_{m}^{M} \sum_{n}^{N} \sum_{t}^{T}\left(W_{i, j, m, n, t}^{A B} \times C_{i, j, m, n, t}^{W A B}+W_{m, n, i, j, t}^{B A} \times C_{m, n, i, j, t}^{W B A}\right)
\end{aligned}
$$

\section{Restrições}

Atendimento da demanda nas instalações de processamento ou escoamento da Empresa A Garante o atendimento da demanda das instalações de processamento ou escoamento da Empresa A:

$$
\sum_{i}^{I} X_{i, j, t}+\sum_{i}^{I} \sum_{m}^{M} \sum_{n}^{N}\left(W_{i, j, m, n, t}^{A B}+W_{m, n, i, j, t}^{B A}\right) \geq D_{j, t}^{A} \quad, \forall j \in J, \forall t \in T
$$

Atendimento da demanda nos clientes da Empresa B

Garante o atendimento da demanda dos clientes da empresa B:

$$
\sum_{m}^{M} Y_{m, n, t}+\sum_{i}^{I} \sum_{j}^{J} \sum_{m}^{M}\left(W_{i, j, m, n, t}^{A B}+W_{m, n, i, j, t}^{B A}\right) \geq D_{n, t}^{B} \quad, \forall n \in N, \forall t \in T
$$

Cumprimento do BP da Empresa A

Garante o atendimento das metas de $B P$ da Empresa A:

$$
\begin{aligned}
& X_{i, j, t}+\sum_{m}^{M} \sum_{n}^{N}\left(W_{i, j, m, n, t}^{A B}+W_{m, n, i, j, t}^{B A}\right) \geq B_{i, j, t}^{A} \times\left(1-F_{i, j, t}^{A}\right) \\
& , \forall i \in I, \forall j \in J, \forall t \in T
\end{aligned}
$$

Cumprimento do BP da Empresa B

Garante o atendimento das metas de $B P$ da Empresa B:

$$
\begin{aligned}
& Y_{m, n, t}+\sum_{i}^{I} \sum_{j}^{J}\left(W_{i, j, m, n, t}^{A B}+W_{m, n, i, j, t}^{B A}\right) \geq B_{m, n, t}^{B} \times\left(1-F_{m, n, t}^{B}\right) \\
& , \forall m \in M, \forall n \in N, \forall t \in T
\end{aligned}
$$

Estoque mínimo para instalações de armazenagem da Empresa A

Garante o estoque mínimo nas instalações de armazenagem da Empresa A:

$$
E_{i, t}^{A} \geq E_{i, t}^{A M} \quad, \forall i \in I, \forall t \in T
$$

Estoque máximo para instalações armazenagem da Empresa A Garante que os estoques máximos nas instalações de armazenagem da Empresa A não sejam ultrapassados: 


$$
E_{i, t}^{A} \leq E_{i, t}^{A X} \quad, \forall i \in I, \forall t \in T
$$

Cálculo do estoque para instalações armazenagem da Empresa A

Continuidade do estoque nas instalações de armazenagem da Empresa A:

Para o primeiro período:

$$
E_{i,(t=1)}^{A}=E_{i,(t=1)}^{A B P}+E_{i}^{I} \quad, \forall i \in I
$$

Para os demais períodos:

$$
\begin{aligned}
& E_{i, t}^{A}=E_{i,(t-1)}^{A}-\sum_{j}^{J} X_{i, j,(t-1)}+E_{i,(t-1)}^{A B P}-\sum_{j}^{J} \sum_{m}^{M} \sum_{n}^{N}\left(W_{i, j, m, n,(t-1)}^{A B}+W_{m, n, i, j,(t-1)}^{B A}\right) \\
& , \forall i \in I, \forall t \in T, t \geq 2
\end{aligned}
$$

Cálculo do custo total e das parcelas das rotas compostas Ao denominar-se uma rota composta feita pela Empresa A seguida pela Empresa B, considera-se que ela é assim realizada:

$\checkmark$ (A). Carregamento produto Empresa A na origem de índice $i$; deslocamento e descarregamento para destino de índice $j$;

$\checkmark$ (B). Deslocamento vazio do ponto de índice $j$ para o ponto de índice $m$; eventual operação para deixar equipamentos compatíveis com produto da Empresa B;

$\checkmark$ (C). Carregamento produto empresa B na origem de índice $m$; deslocamento e descarregamento para destino de índice $n$.

No caso de operações isoladas, a Empresa A pagaria os custos das operações descritas em (A) e a Empresa B pagaria os custos das operações descritas em (C). No caso de uma operação em conjunto, gerando uma rota conjugada, há o custo das operações descritas em (B); a questão a ser respondida é: como este custo deve ser dividido entre as empresas? Sabese, por hipóteses adotadas no trabalho, que uma rota conjugada é $6 \%$ mais barata que uma rota simples. Continuando com o exemplo apresentado, se considerarmos que o custo da rota simples da operação descrita em $(\mathrm{A})$ seja $\mathrm{C}^{\mathrm{A}}$ e analogamente para $(\mathrm{C})$ tenhamos $\mathrm{C}^{\mathrm{C}}$ e que as operações descritas em $(B)$ seja $C^{\mathrm{B}}$, podemos escrever a seguinte equação:

$$
\left(C^{A}+C^{C}\right) \times 0,06<C^{B}
$$

Caso a equação (9) seja satisfeita temos duas rotas simples possíveis de serem conjugadas, considerando somente a questão espacial.

Adota-se agora que $\mathrm{C}^{\mathrm{A}}$, seja o custo a ser pago pela Empresa A em uma rota conjugada e analogamente $\mathrm{C}^{\mathrm{C}}$. Então consideremos, para efeitos de cálculo no modelo, a seguinte hipótese para a divisão de custos em uma rota conjugada:

$$
\begin{aligned}
& \checkmark \text { Empresa A: } C^{A}{ }^{\prime}=C^{A}+\frac{C^{A}}{\left(C^{A}+C^{C}\right)} \times C^{B} \\
& \checkmark \text { Empresa B: } C^{C}{ }^{\prime}=C^{C}+\frac{C^{C}}{\left(C^{A}+C^{C}\right)} \times C^{B}
\end{aligned}
$$


Definem-se então os seguintes parâmetros adicionais:

$\checkmark C^{T A}$ é o custo total em R\$ de frete da Empresa A; e $C^{T B}$ é o mesmo custo para B;

$\checkmark C_{i, j, m, n, t}^{W A A B}$ parcela do custo total do frete destinada para Empresa A, em $\mathrm{R} \$ / \mathrm{t}$., para a rota conjugada com uma rota de origem de índice $i$ para o destino de índice $j$ seguido de outra rota de origem de índice $m$ para o destino de índice $n$ no período de tempo de índice $t$;

$\checkmark C_{i, j, m, n, t}^{W B A B}$ parcela do custo total do frete destinada para a Empresa B, em R\$/t. para a rota conjugada com uma rota de origem de índice $i$ para o destino de índice $j$ seguido de outra rota de origem de índice $m$ para o destino de índice $n$ no período de tempo de índice $t$.

Analogamente defini-se para uma rota conjugada feita pela Empresa B seguida pela A:

$\checkmark C_{m, n, i, j, t}^{W A B A}$ parcela do custo total do frete destinada para Empresa A, em $\mathrm{R} \$ / \mathrm{t}$., para a rota conjugada com uma rota de origem de índice $m$ para o destino de índice $n$ seguido de outra rota de origem de índice $i$ para o destino de índice $j$ no período de tempo de índice $t$;

$\checkmark C_{m, n, i, j, t}^{W B B A}$ parcela do custo total do frete destinada para a Empresa B, em R\$/t. para a rota conjugada com uma rota de origem de índice $m$ para o destino de índice $n$ seguido de outra rota de origem de índice $i$ para o destino de índice $j$ no período de tempo de índice $t$;

$\checkmark$ Sabe-se também que: $C^{T A}+C^{T B}=C^{T}$.

Vale ressaltar que os Custos de rotas simples $\left(C^{T A}\right.$ e $\left.C^{T B}\right)$ relacionam-se com os de rotas conjugadas (índice $w$ ), de forma que as rotas simples se conjugam em rotas cruzadas, gerando carga de retorno e, portanto a economia de frete procurada.

Os fatores de Flexibilização $f$ não inviabilizam as restrições de atendimento do BP das empresas, tão pouco se conflitam; isto porque os BPs serão cumpridos à medida que toda a carga planejada será movimentada com o menor custo, pois só haverá flexibilização se a conjugação de cargas gerar economia maior do que os custos da flexibilização. Para melhor apreciação dos resultados do modelo alguns valores de referência são assim calculados:

Custo Total Empresa A:

$$
\begin{aligned}
& C^{T A}=\sum_{i}^{I} \sum_{j}^{J} \sum_{t}^{T}\left(X_{i, j, t} \times C_{i, j, t}^{X}\right)+ \\
& +\sum_{i}^{I} \sum_{j}^{J} \sum_{m}^{M} \sum_{n}^{N} \sum_{t}^{T}\left(W_{i, j, m, n, t}^{A B} \times C_{i, j, m, n, t}^{W A A B}+W_{m, n, i, j, t}^{B A} \times C_{m, n, i, j, t}^{W A B A}\right)
\end{aligned}
$$

$\forall i \in I, \forall j \in J, \forall t \in T, \forall n \in N, \forall m \in N$

Custo Total Empresa B:

$$
\begin{aligned}
& C^{T B}=\sum_{m}^{M} \sum_{n}^{N} \sum_{t}^{T}\left(Y_{m, n, t} \times C_{m, n, t}^{Y}\right)+ \\
& +\sum_{i}^{I} \sum_{j}^{J} \sum_{m}^{M} \sum_{n}^{N} \sum_{t}^{T}\left(W_{i, j, m, n, t}^{A B} \times C_{i, j, m, n, t}^{W B A B}+W_{m, n, i, j, t}^{B A} \times C_{m, n, i, j, t}^{W B B A}\right)
\end{aligned}
$$




\subsection{Nível Tático}

Os Planejamentos Estratégicos (BP) das empresas, a partir da metodologia proposta, dão origem a um BP único com foco na logística e mais especificamente na movimentação das cargas das empresas A e B. O objetivo é seqüencial a movimentação dos estoques do produto da empresa A de modo a maximizar a conjugação das cargas no momento da execução.

O BP consolidado das empresas reflete também a anuência das áreas de negócio na aceitação de todas ou parte das recomendações oriundas da saída do modelo matemático no nível estratégico; como colocado anteriormente, a escolha se dá através da opção por um dos cenários que o modelo oferece. O cenário escolhido define então o planejamento logístico para o ano em exercício, rematando o equilíbrio entre as necessidades das áreas comercial e logística da empresa A e as possibilidades de conjugação de cargas com a empresa B.

O objetivo do modelo matemático no Nível Tático é, a partir de um planejamento de transporte, gerar todas as possibilidades de conjugação de cargas no médio prazo e fornecer subsídio para a interação com as áreas autorizadas a flexibilizar as janelas de tempo.

O "médio prazo" aqui é medido em meses, sendo o primeiro firme, ou seja, o primeiro mês de planejamento no nível tático não sofrerá mudanças no planejamento subseqüente. Esse é o conceito de "horizonte volante" ou "planejamento rolante", e nesta tese o número de meses utilizado na aplicação é dois.

As Variáveis de Decisão no Nível Tático são:

1. Rotas e Cargas com conjugação possível que não atendam às janelas de tempo primárias, para a apresentação e negociação com os níveis de gestão das empresas;

2. Rotas e Cargas de impossível conjugação nesse horizonte de programação (enviada à interação no nível estratégico).

Entrada de Dados: planejamento de vendas de B e de transporte de A.

Horizonte de Programação: quatro semanas.

A Nomenclatura dos Índices e Parâmetros seguem a mesma linha apresentada para o modelo estratégico. Como o adicional que segue:

$\checkmark P_{i, j, t}^{A} \ldots$ Planejamento de rotas da Empresa A para a rota de origem de índice $i$ para o destino de índice $j$ no período de tempo de índice $t$;

$\checkmark P_{m, n, t}^{B} \ldots$ Planejamento de rotas da Empresa B para a rota de origem de índice $m$ para o destino de índice $n$ no período de tempo de índice $t$.

Relativo aos fatores de flexibilização:

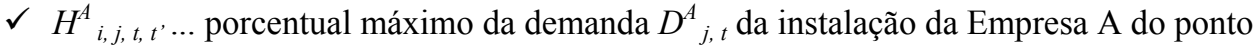
de índice $j$ que é atendido pelo ponto de armazenagem do ponto de índice $i$, que pode ser transferida para do período de tempo de índice $t$ para o período de tempo de índice $t^{\prime}$;

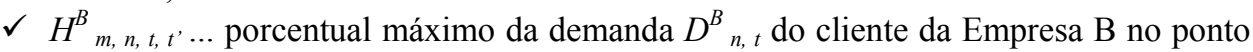
de índice $n$ que é atendido pela fábrica de índice $m$, que pode ser transferida para do período de tempo de índice $t$ para o período de tempo de índice $t^{\prime}$;

$\checkmark Z_{i, j, t, t}^{A} \ldots$ quantidade, em toneladas, da demanda $D_{j, t}^{A}$ da instalação da Empresa A do ponto de índice $j$ remanejada do período de tempo de índice $t$ para o período de tempo de índice $t^{\prime}$; 
$\checkmark Z_{m, n, t, t^{\prime}}^{B} \ldots$ quantidade, em toneladas, da demanda $D^{B}{ }_{n, t}$ do cliente da Empresa B do ponto de índice $n$ remanejada do período de tempo de índice $t$ para o período de tempo de índice $t^{\prime}$.

Função objetivo:

Função com objetivo de minimizar a conta frete de todo o sistema. Na inexistência das rotas conjugadas (variáveis $W$ ), minimizaria o custo da conta frete das duas empresas considerando uma operação totalmente estanque da outra:

$$
\begin{aligned}
& C^{T}=\sum_{i}^{I} \sum_{j}^{J} \sum_{t}^{T}\left(X_{i, j, t} \times C_{i, j, t}^{X}\right)+\sum_{m}^{M} \sum_{n}^{N} \sum_{t}^{T}\left(Y_{m, n, t} \times C_{m, n, t}^{Y}\right)+ \\
& +\sum_{i}^{I} \sum_{j}^{J} \sum_{m}^{M} \sum_{n}^{N} \sum_{t}^{T}\left(W_{i, j, m, n, t}^{A B} \times C_{i, j, m, n, t}^{W A B}+W_{m, n, i, j, t}^{B A} \times C_{m, n, i, j, t}^{W B A}\right)
\end{aligned}
$$

\section{Restrições}

Atendimento da demanda nas instalações de processamento ou escoamento da Empresa A Garante o atendimento da demanda das instalações de processamento ou escoamento da Empresa A:

$$
\begin{aligned}
& \sum_{i}^{I} X_{i, j, t}+\sum_{i}^{I} \sum_{m}^{M} \sum_{n}^{N}\left(W_{i, j, m, n, t}^{A B}+W_{m, n, i, j, t}^{B A}\right) \geq \\
& \geq D_{j, t}^{A}-\sum_{i}^{I} \sum_{t^{\prime} \neq t}^{T} Z^{A}{ }_{i, j, t, t^{\prime}}+\sum_{i}^{I} \sum_{t^{\prime} \neq t}^{T} Z^{A}{ }_{i, j, t^{\prime}, t}
\end{aligned} \quad, \forall j \in J, \forall t \in T
$$

Atendimento da demanda nos clientes da Empresa B

Garante o atendimento da demanda dos clientes da empresa B:

$$
\begin{array}{ll}
\sum_{m}^{M} Y_{m, n, t}+\sum_{i}^{I} \sum_{j}^{J} \sum_{m}^{M}\left(W_{i, j, m, n, t}^{A B}+W_{m, n, i, j, t}^{B A}\right) \geq & \\
\geq D^{B}{ }_{n, t}-\sum_{m}^{M} \sum_{t^{\prime} \neq t}^{T} Z^{B}{ }_{m, n, t, t^{\prime}}+\sum_{m}^{M} \sum_{t^{\prime} \neq t}^{T} Z^{B}{ }_{m, n, t^{\prime}, t} & , \forall n \in N, \forall t \in T
\end{array}
$$

Cumprimento do Planejamento de rotas da Empresa A

Garante o atendimento das metas do planejamento de rotas da Empresa A:

$$
\begin{aligned}
& X_{i, j, t}+\sum_{m}^{M} \sum_{n}^{N}\left(W_{i, j, m, n, t}^{A B}+W_{m, n, i, j, t}^{B A}\right) \geq P_{i, j, t}^{A}-\sum_{t^{\prime} \neq t}^{T} Z_{i, j, t, t^{\prime}}^{A}+\sum_{t^{\prime} \neq t}^{T} Z^{A}{ }_{i, j, t^{\prime}, t} \\
& , \forall i \in I, \forall j \in T, \forall t \in T
\end{aligned}
$$

Cumprimento do Planejamento de rotas da Empresa B

Garante o atendimento das metas do planejamento de rotas da Empresa B:

$$
\begin{aligned}
& Y_{m, n, t}+\sum_{i}^{I} \sum_{j}^{J}\left(W_{i, j, m, n, t}^{A B}+W_{m, n, i, j, t}^{B A}\right) \geq P_{m, n, t}^{B}-\sum_{t^{\prime} \neq t}^{T} Z_{m, n, t, t^{\prime}}^{B}+\sum_{t^{\prime} \neq t}^{T} Z_{m, n, t^{\prime}, t}^{B} \\
& , \forall m \in M, \forall n \in N, \forall t \in T
\end{aligned}
$$


Máximo remanejamento no Planejamento de rotas da Empresa A

Garante que não haja mais remanejamento na Empresa A do o que permitido:

$$
Z_{i, j, t, t^{\prime}}^{A} \leq P_{i, j, t}^{A} \times H_{i, j, t, t^{\prime}}^{A} \quad, \forall i \in I, \forall j \in J, \forall t \in T, \forall t^{\prime} \in T, t \neq t
$$

Máximo remanejamento no Planejamento de rotas da Empresa B

Garante que não haja mais remanejamento na Empresa A do o que permitido:

$$
Z_{m, n, t, t^{\prime}}^{B} \leq P_{m, n, t}^{B} \times H_{m, n, t, t^{\prime}}^{B} \quad, \forall m \in M, \forall n \in N, \forall t \in T, t \neq t
$$

Balanço dos remanejamentos da Empresa A

Garante que os remanejamentos na Empresa A não sejam superiores a demanda em cada ponto e período:

$$
D_{j, t}^{A}-\sum_{i}^{I} \sum_{t^{\prime} \neq t}^{T} Z^{A}{ }_{i, j, t, t^{\prime}}+\sum_{i}^{I} \sum_{t^{\prime} \neq t}^{T} Z^{A}{ }_{i, j, t^{\prime}, t} \geq 0 \quad, \forall j \in J, \forall t \in T
$$

Balanço dos remanejamentos da Empresa B

Garante que os remanejamentos na Empresa B não sejam superiores a demanda em cada ponto e período:

$$
D_{n, t}^{B}-\sum_{i}^{I} \sum_{t^{\prime} \neq t}^{T} Z_{m, n, t, t^{\prime}}^{B}+\sum_{i}^{I} \sum_{t^{\prime} \neq t}^{T} Z_{m, n, t^{\prime}, t}^{B} \geq 0 \quad, \forall i \in I, \forall t \in T
$$

Nota: As relações existentes entre as restrições do modelo Estratégico e do modelo tático estão fundamentadas que no modelo estratégico o planejamento é um forecast (previsão); já no modelo tático as restrições e a própria função objetivo tratam de planejamentos firmes, vendas já realizadas; além claro dos horizontes de tempo.

\subsection{Nível Operacional}

O planejamento realizado por meio da modelagem matemática buscou maximizar a possibilidade de conjugação de cargas, e assim o transporte colaborativo entre as empresas A e B; porém a sua execução é dependente da confirmação da carteira de pedidos de venda do produto de $\mathrm{B}$ e efetivação do fluxo do produto de A, restando apenas programar as viagens simples e conjugadas e ordenar a execução. Por esta razão não cabe novo modelo matemático, mas sim empenhar esforços para buscar realizar a proposta do planejamento. O processo de programação de viagens finaliza o ciclo atendendo à demanda de cargas da semana.

\section{Aplicação da Metodologia e Resultados Obtidos}

A movimentação da soja inicia-se com processo de transporte a partir do agricultor para os silos de armazenamento e daí para as unidades expedidoras e/ou processadoras, ou o transporte é direto do produtor para as unidades processadoras ou portos para exportação; já no caso do grão processado, o transporte tem origem nas unidades processadoras com destino a consumidores fabris, no mercado doméstico e para exportação (como o caso do farelo de soja).

O volume de soja transportado por ferrovia vem aumentando significativamente nos últimos anos, com a privatização do setor ferroviário, alcançando a casa de $28 \%$; porém a grande parcela, $67 \%$ da soja, é movimentada no modal rodoviário; sendo este então o modal utilizado para a aplicação da pesquisa. 


\subsection{Parâmetro de redução de fretes para cargas efetivamente conjugadas e cálculo dos fretes reais equivalentes por distância}

$\mathrm{Na}$ metodologia, desenvolvida e amparada em modelagem matemática, o desconto obtido com a conjugação de carga é um parâmetro, e pode ser determinado região a região e manipulado de modo a ser elevado ou diminuído. Os fatores mais importantes a serem considerados para esta decisão são:

- balanceamento entre a rota principal e retorno;

- sazonalidades determinando alta ou baixa das movimentações do sistema;

- interesse em incentivar determinado fluxo;

- fator competitivo, buscando cativar os transportadores que servem aos concorrentes.

Um valor módico e coerente com as práticas reais de mercado para o de desconto do frete na conjugação de cargas é $\mathbf{6 \%}$, este será adotado também nos modelos matemáticos, sobre os fretes reais (soma dos fretes unitários do ciclo original de ida e volta), cada vez que uma viagem conjugada for concretizada. Vale ressaltar que o objetivo do trabalho é criar uma metodologia consistente e eficaz com qualquer parâmetro de desconto, e o parâmetro escolhido (pequeno, e sustentável em qualquer condição) valoriza os resultados obtidos.

Os fretes "reais" utilizados pelo modelo matemático foram extraídos da base de dados (valores efetivamente praticados) e receberam tratamento estatístico.

Esta análise estatística teve como objetivo estabelecer padrões de fretes praticados por rota, e por região. Isto se fez necessário para estabelecer fretes equivalentes por distância facilitando a implementação.

\subsection{Implementação da metodologia por pólo geográfico}

O pólo escolhido para a aplicação foi Rio Grande do Sul. As razões fundamentais para implementação por pólo geográfico são:

- Os caminhões fixam-se estabelecendo pólos, no período produtivo da região;

- Uma "central nacional" estaria focada na região de maior movimento no momento e perderia menores volumes de outras, mas com carga possível de conjugar;

- Não há sinergia entre regiões distantes ou corredores de transportes diferentes.

\subsection{Cenários estudados}

Os cenários escolhidos estão descritos nas Tabelas 2 e 3, e a análise representada nos gráficos mostra os resultados do cenário R3a (como exemplo do trabalho completo realizado): BP com rotas conjugadas, nenhuma flexibilidade de alteração do BP e com $100 \%$ de remanejamento para 1 semana e $50 \%$ para 2 semanas. A Figura 2 traz um gráfico representativo do Custo Total, em milhões de reais, da saída do modelo estratégico para cada um dos cenários. Na seção 6.4 a Tabela 4 traz a compilação dos resultados do modelo tático e, portanto, os resultados finais da aplicação, já que engloba os resultados do modelo estratégico e nesta aplicação não cabe atuação no nível operacional, pois é realizada a posteriori (base de dados decorrida na prática). 
Tabela 2 - Cenário para o modelo Estratégico.

\begin{tabular}{|c|l|}
\hline MODELO & DESCRIÇÃO \\
\hline R1 & Business Plan, sem rota composta \\
\hline R2 & Otimizado (nenhum vínculo com Business Plan), sem rota conjugada \\
\hline R3 & Business Plan, com rota conjugada, nenhuma flexibilidade de alteração do BP \\
\hline R4 & Business Plan, com rota conjugada, com $20 \%$ de flexibilidade de alteração do BP da empresa A \\
\hline R5 & Business Plan, com rota conjugada, com $40 \%$ de flexibilidade de alteração do BP da empresa A \\
\hline R6 & Business Plan, com rota conjugada, com $60 \%$ de flexibilidade de alteração do BP da empresa A \\
\hline R7 & Business Plan, com rota conjugada, com $80 \%$ de flexibilidade de alteração do BP da empresa A \\
\hline R8 & Business Plan, com rota conjugada, com total flexibilidade de alteração do BP da empresa $\mathbf{A}$ \\
\hline
\end{tabular}

Tabela 3 - Cenário para o modelo Tático.

\begin{tabular}{|c|l|}
\hline MODELO & DESCRIÇÃo \\
\hline R1 & BP, sem rota composta \\
\hline R3a & BP, com rota conjugada, nenhuma flexibilidade de alteração do BP e com $100 \%$ de remanejamento para 1 semana e $50 \%$ para 2 semanas \\
\hline R3b & BP, com rota conjugada, nenhuma flexibilidade de alteração do BP e com $75 \%$ de remanejamento para 1 semana \\
\hline R3c & BP, com rota conjugada, nenhuma flexibilidade de alteração do BP e sem remanejamento \\
\hline R8a & BP, com rota conjugada, total flexibilidade de alteração do BP da empresa A e com $100 \%$ de remanejamento para 1 semana e $50 \%$ para 2 semanas \\
\hline R8b & BP, com rota conjugada, total flexibilidade de alteração do BP da empresa A e com $75 \%$ de remanejamento para 1 semana \\
\hline R8c & BP, com rota conjugada, total flexibilidade de alteração do BP da empresa A e sem remanejamento \\
\hline
\end{tabular}

\subsection{Implementação e Resultados}

Este caso tratará o problema proposto com um número reduzido de índices e variáveis. A redução do número de dimensões foi realizada empregando-se instrumentos de geoinformação, na tentativa de gerar o máximo de informações agregadas em tabelas, ilustrações gráficas e mapas. Após a definição das dimensões e parâmetros do estudo de caso, foi efetuado o processamento computacional (Microcomputador com processador marca Intel e capacidade de um giga hertz). Este caso foi implementado utilizando-se como linguagem de manipulação algébrica o GAMS 2.50 (Brooke et al., 1997) e o ILOG CPLEX 7.0 como solver (tempo de processamento de 2,5h por cenário). O emprego do GAMS facilita a codificação do modelo e das suas diversas instâncias ou cenários e o uso do ILOG CPLEX é recomendado para problemas combinatórios de médio/grande porte (Hino, 1999). $\mathrm{O}$ estudo de caso envolve: Trinta e duas fazendas, agregadas em microrregiões pelo IBGE, para o Estado do Rio Grande do Sul; onze silos, três fábricas; um porto (Rio Grande); doze períodos de tempo, representando os meses, associados a cinqüenta e duas semanas, num período de um ano.

No que tange ao modelo estratégico, os cenários R1 e R2 não trabalham a conjugação de cargas e espelham condições originais da empresa A. Para os cenários de R3 a R8 o modelo matemático busca o máximo de conjugação de cargas graduando a flexibilização do BP de A, traduzindo-se em redução da conta de frete total frente ao BP original. De fato, a graduação na flexibilização do $\mathrm{BP}$ da empresa $\mathrm{A}$ começa no cenário $\mathrm{R} 4$; a redução é continuamente obtida, mas a proporção vai diminuindo com o aumento da flexibilização; desta forma, o cenário R8 é o que possui menor custo de transporte total. Com a implantação da metodologia no mercado real, as interações, como as que são simuladas nesta etapa do trabalho, vão permitir a análise dos ganhos de frete comparados com os custos financeiros ou comerciais para a aceitação da flexibilização proposta para o $\mathrm{BP}$, com equilíbrio entre os interesses das empresas e áreas. 


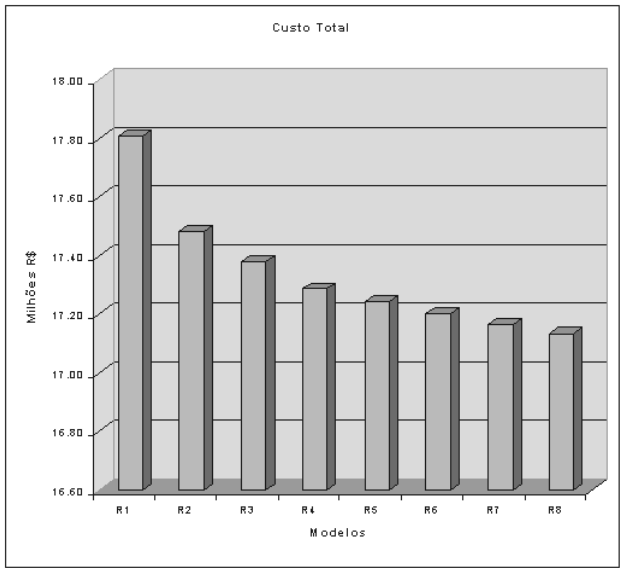

Figura 2 - Custo total, em milhões de reais, do modelo estratégico, para os cenários.

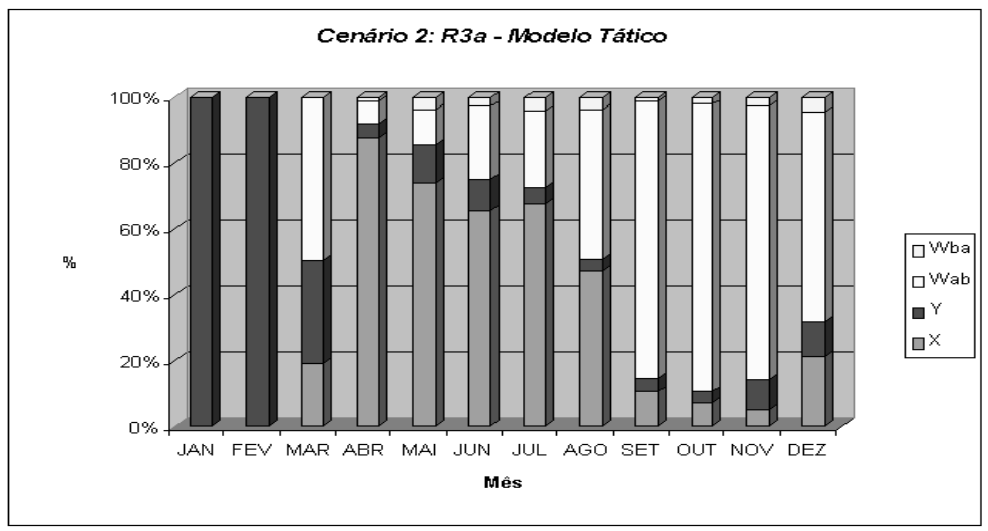

Figura 3 - Resultado do BP para o cenário R3a, no caso do modelo tático.

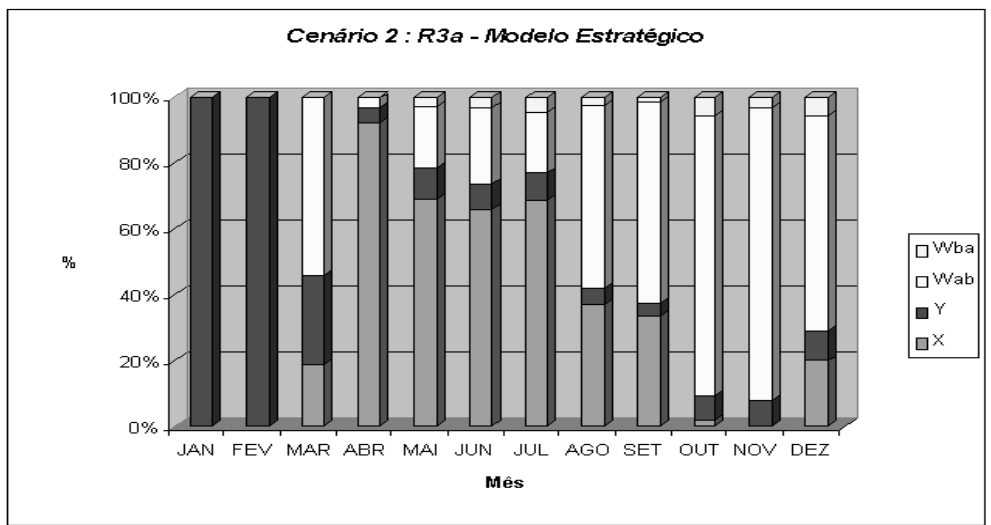

Figura 4 - Resultado do BP para o cenário R3a, no caso do modelo estratégico. 
Tabela 4 - Resultados finais da implementação metodologia para a região geográfica Sul.

\begin{tabular}{|c|c|c|c|c|c|}
\hline \multicolumn{2}{|r|}{ Cenário } & \multirow{2}{*}{$\begin{array}{c}\begin{array}{c}\text { Custo Total } \\
\text { (RS) }\end{array} \\
17.807 .921,43\end{array}$} & \multirow{2}{*}{\begin{tabular}{c|} 
CTA $(\mathrm{R} \$)$ \\
$13.301 .419,36$
\end{tabular}} & \multirow{2}{*}{$\begin{array}{l}\text { CTB }(\mathrm{R} \$) \\
4.506 .502,08\end{array}$} & \multirow[t]{2}{*}{$\begin{array}{c}\text { Redução } \\
\text { qto ao } \\
\text { anterior }\end{array}$} \\
\hline $\mathbf{R} 1$ & BP, sem rota composta & & & & \\
\hline R3a & $\begin{array}{l}\text { BP, com rota conjugada, nenhuma flexibilidade de alteração do BP e com } \\
100 \% \text { de remanejamento para } 1 \text { semana e } 50 \% \text { para } 2 \text { semanas }\end{array}$ & $17.365 .152,60$ & $13.177 .336,03$ & $4.187 .816,57$ & $2,49 \%$ \\
\hline R3b & $\begin{array}{l}\text { BP, com rota conjugada, nenhuma flexibilidade de alteração do BP e com } \\
75 \% \text { de remanejamento para } 1 \text { semana }\end{array}$ & $17.367 .604,21$ & $13.174 .290,70$ & $4.193 .313,51$ & $-0,01 \%$ \\
\hline $\mathbf{R 3 c}$ & $\begin{array}{l}\text { BP, com rota conjugada, nenhuma flexibilidade de alteração do BP e sem } \\
\text { remanejamento }\end{array}$ & $17.399 .748,87$ & $13.139 .350,87$ & $4.260 .398,01$ & $-0,19 \%$ \\
\hline R8a & $\begin{array}{l}\text { BP, com rota conjugada, com total flexibilidade de alteração do BP da } \\
\text { empresa A e com } 100 \% \text { de remanejamento para } 1 \text { semana e } 50 \% \text { para } \\
2 \text { semanas }\end{array}$ & $17.120 .343,42$ & 12.936.609,52 & 4.183.733,90 & $1,61 \%$ \\
\hline R8b & $\begin{array}{l}\text { BP, com rota conjugada, com total flexibilidade de alteração do BP da } \\
\text { empresa A e com } 75 \% \text { de remanejamento para } 1 \text { semana }\end{array}$ & $17.122 .218,57$ & $12.935 .241,81$ & $4.186 .976,76$ & $-0,01 \%$ \\
\hline R8c & $\begin{array}{l}\text { BP, com rota conjugada, com total flexibilidade de alteração do BP da } \\
\text { empresa A e sem remanejamento }\end{array}$ & $17.153 .884,01$ & $12.900 .451,43$ & $4.253 .432,59$ & $-0,18 \%$ \\
\hline \multicolumn{2}{|r|}{ Melhor Resultado sobre BP original } & $3,86 \%$ & & & \\
\hline \multicolumn{2}{|r|}{ Redução obtida/redução máxima possível (6\%) } & $63,33 \%$ & & & \\
\hline
\end{tabular}

Para o modelo tático e conseqüentemente para a aplicação, o qual recebeu os cenários 3 e 8 a partir do estratégico. Nesta fase da metodologia, as iterações trataram de flexibilização das janelas de tempo para as entregas do produto da empresa B. As flexibilizações dependem da anuência das áreas de negócio; em condições reais, esta etapa interativa é mais complicada porque, enquanto no nível estratégico as mudanças do BP quanto ao seqüenciamento são mais técnicas, neste caso as alterações dependem de questões quase que totalmente comerciais; além disso, as interfaces acontecem em número muito grande e em cascata. Os responsáveis pelo projeto de Transporte Colaborativo executam o modelo matemático e consultam os vendedores da empresa B que, por sua vez, ou assumem a responsabilidade pela mudança do momento acordado para a entrega ou realizam a consulta diretamente ao cliente. Essa operação não inviabiliza a metodologia já que a compra de fertilizante acontece com certo planejamento, e muitas vezes engloba transações de outros produtos como defensivos ou sementes na mesma comercialização; também vem acontecendo, de forma freqüente, a troca de fertilizantes por soja. Estes elementos fazem com que a expectativa de recebimento do fertilizante comprado seja contada em semanas e não em dias; mesmo assim, a janela de entrega deve estar restrita a períodos curtos, daí a decisão de operar no modelo matemático desta pesquisa com no máximo 2 semanas de flexibilização. O resultado final mostrou o cenário R8a como o de maior redução no custo total de frete; este cenário permite flexibilizar totalmente o BP da Empresa A, e para a Empresa B 100\% de remanejamento para a primeira semana e $50 \%$ para a segunda.

As premissas elaboradas para a formação do cenário R8a são factíveis mediante uma interação eficaz junto ao mercado e contínua interação com a realidade; vale ressaltar que o segundo autor desta pesquisa e autor da tese de doutorado que deu origem a ela exercia, na oportunidade, cargo executivo na área de logística na empresa que cedeu os dados e assim teve a oportunidade de validá-los na prática.

\section{Conclusões}

O resultado da aplicação da metodologia atinge sua meta pelas economias de frete obtidas, mas também promove colaboração efetiva entre as empresas. Uma extrapolação simplista do resultado obtido no pólo geográfico sul, utilizando como premissa a economia de 3,86\% na 
conta-frete global, projeta um resultado de $\mathrm{R} \$ 12.730 .670,46$ no ano, para toda a base de dados disponível, ou seja, todo o volume movimentado pelas Empresas A e B no ano.

O método proposto é simples e o grau de dificuldade para a implementação dos modelos matemáticos é baixo, uma vez que programação linear é uma ferramenta já comum na solução de problemas em transporte, inclusive nas empresas e não só nos meios acadêmicos.

A formalização do processo favorece o entrosamento natural entre as empresas, através das atividades conjuntas:

1- o planejamento estratégico de negócio,

2- o planejamento tático de médio prazo, e

3- a execução operacional do transporte.

Este exercício torna ambas as empresas mais fortes e competitivas, fomentando práticas como: troca de conhecimento; redução de gastos com planejamento; redução de gastos com operação; maior poder de negociação com fornecedores; maior capilaridade na distribuição e, por conseqüência, possibilidade de alcançar novos mercados; vantagem competitiva; fidelização dos recursos de transporte, entendendo-se aqui carreteiros autônomos como principais recursos de transporte. São itens importantes e trazem resultados reais às empresas, e em sua maioria são mensuráveis em valores monetários; entretanto, destaca-se a garantia dos recursos de transporte por meio da fidelização de carreteiros autônomos. É certo que, não haverá recursos de transportes suficientes no médio prazo com o crescimento projetado para o Brasil, tanto em infra-estrutura quanto em equipamentos (caminhões, vagões, etc.).

A colaboração na logística, e mais especificamente no transporte, é ainda mais interessante para o carreteiro que para as empresas patrocinadoras do projeto porque: minimiza a busca por transporte de retorno, longas demoras para operações de carga e descarga, e portanto perda de lucratividade. Com a implementação do transporte colaborativo as empresas ganham em frete e detêm o caminhão em seu sistema, gerando forte vantagem competitiva frente aos concorrentes que não se utilizam deste processo. O sistema, como um todo, ganha com a implementação do Transporte Colaborativo através da metodologia proposta nesta pesquisa; ganha em produtividade, em custos, em organização e em garantia de recursos que, em última instância, garante a perpetuação do negócio.

\section{Referências Bibliográficas}

(1) Adler, J.L. \& Blue, V.J. (1998). Toward The Design of Intelligent Traveler Information Systems. Transportation Research (Part C), 6(3), 157-172, Elsevier Science.

(2) Allen, E. (1998). Supply Chain Management Software. Vendor Comparison and Analysis, University of Texas, EUA.

(3) Bachem, A.; Hochstättler, W.; Malich, M.; Hochstättler, W. \& Malich, M. (1993). The simulated Trading Heuristic for solving Vehicle Routing Problems. EUA.

(4) Badeau, P.; Potvin, J.Y.; Guertin, F.; Taillard, E.; \& Gendreau, M. (1997). A parallel tabu search heuristic for the vehicle routing problem with time windows. Transportation Research (Part C), 5(2), 109-122, Elsevier Science, EUA.

(5) Baita, F.; Pesenti, R. \& Favareto, D. (1998). Dynamic routing-and-inventory problems: a review. Transportation Research (Part A), 32(8), 585-598, Elsevier Science, EUA. 
(6) Baita, F.; Pesenti, R.; Ukovich, W. \& Favareto, D. (2000). A Comparison of Different Solution Approaches to the Vehicle Scheduling Problem in a Practical Case. Computers \& Operations Research, 27(13), 1249-1269, Elsevier Science.

(7) Baldwin, C.Y. (2000). Harvard Business Review: On managing the value chain. Boston, EUA.

(8) Ballou, R.H. (1999). Business Logistics Management. $4^{\text {a }}$ edição, Prentice Hall, EUA.

(9) Ballou, R.H. (1992). Logística Empresarial. São Paulo, Brasil.

(10) Ben-Akiva, M. \& Lerman, S.R. (2000). Discrete Choice Analysis: Theory and Application to travel Demand. MIT Press Series in transportation studies, Cambridge, EUA.

(11) Bodin, L.D.; Fagan, G.; Welebny, R. \& Greenberg, J. (1983). Routing and scheduling of vehicles and crews: The state of the art. Computers \& Operations Research, 10(2).

(12) Bowersox, D.J. \& Closs, D.J. (1996). Logistical Management: The Integrated Supply Process. McGraw-Hill, EUA.

(13) Bramel, J. \& Levi, D.S. (1997). The logic of logistics. Springer, EUA.

(14) Brooke, A.; Kendrick, D.; Meeraus, A. \& Raman, R. (1997). Gams: A User's Guide. Ed. Edgard Blücher, GAMS Development Corporation, Washington.

(15) Browning, B. \& White, A. (2001). Collaborative Transportation Management - A Proposal. EUA.

(16) Caixeta Filho, J.V. \& Gameiro, H.A. (2001). Sistemas de Gerenciamento de Transportes - Modelagem Matemática. Editora Atlas, São Paulo.

(17) Caixeta Filho, J.V. \& Gameiro H.A. (2001). Transporte e Logística em Sistemas Agroindustriais. Editora Atlas, São Paulo.

(18) Caixeta Filho, J.V. (2001). Logística e Transporte no Agronegócio Brasileiro. Revista "Preços Agrícolas", Dezembro de 2000/Janeiro de 2001, 3-5.

(19) Caliper (Corp.) (2001). Maptitude: User's Guide Version 4.5. Caliper Corporation.

(20) Cavalcanti Netto, M. (1992). Contribuição ao desenvolvimento de um Sistema logístico de Exportação e Importação de Produtos conteinerizados e suas relações com o Transporte Marítimo. Tese de Doutorado apresentada à Universidade Federal do Rio de Janeiro, Brasil.

(21) Chen, H. \& Boyce, D. (1999). Dynamic Travel Choice Models. Springer. Alemanha.

(22) Copyright Technology Futures (2000). Techniques \& Methodologies Employed by Technology Futures, Inc.

(23) Crainic, G.T. (1998). Fleet Management and logistics. Centre for Research on Transportation, University de Montreal, Canadá.

(24) Cunha, C.B. (1997). Uma contribuição para o problema de roteirização de veículos com restrições operacionais. Tese de Doutorado. Escola Politécnica da Universidade de São Paulo, Brasil. 
(25) Derigs, U.; Grabenbauer, G. \& Golden, B.L. (este último editor do livro) (1993). American Journal of Mathematical \& Management Sciences, 3-4, 250-266, EUA.

(26) Desrochers, J.; Soumis, F.; Belanger, N. \& Ioachim, I. (1999). Fleet Assignment and Routing With Schedule Synchronization Constraints. European Journal of Operation Research, 119(1), 75-90, Elsevier Science.

(27) Desrochers, J.; Desrochers, M. \& Langevin, A. (1990). A two-commodity flow formulation for the travelling salesman and the makespan problems with time windows. Centre Research Transportation of Montreal, Canadá.

(28) Fagerholt, K. (2000). Evaluating the Trade-Off Between the Level of Customer Service and Transportation Costs in a Ship Scheduling Problem. Maritime Policy \& Management.

(29) Fagerholt, K. \& Christiansen, M. (2000). A traveling salesman problem with allocation, time windows and precedence constraints - an application to ship scheduling. International Transactions in Operational Research, 7(3), 231-244, Elsevier Science.

(30) Fagerholt, K. (2000). Ship Scheduling With Soft Time Windows: An Optimization Based Approach. European Journal of Operation Research, 131(3), 559-571, Elsevier Science.

(31) Fu, L. (2001). An adaptive routing algorithm for in-vehicle route guidance systems with real time information. Transportation Research (Part B), 35(8), 749-765, Elsevier Science.

(32) Fu, L. \& Rilett, L.R. (1998). Expected shortest paths in dynamic and stochastic traffic networks. Transportation Research (Part B), 32(7), 499-516, Elsevier Science.

(33) Gendreau, M. \& Pesant, G. (1998). A constraint programming framework for local search methods. Centre Research Transportation of Montreal, Canadá.

(34) Glover, F. (1989). Tabu Search - Part I. ORSA Journal on Computing, 1, EUA.

(35) Glover, F. (1990). Tabu Search - Part II. ORSA Journal on Computing, 2, EUA.

(36) Golden, B.L. (1993). American Journal of Mathematical and Management Sciences, 13(3-4), University of Maryland, EUA.

(37) Haugton, M.A. \& Stenger, A.J. (1997). Semi-Variable delivery routes and efficiency of outbound logistics. Pensylvania State University, EUA.

(38) Hino, C.M. (1999). Desenvolvimento de métodos para elaboração de modelos heurísticos de designação e seqüenciamento de planos de estivagem de navios portacontêineres. Dissertação (Mestrado). Departamento de Engenharia Naval, Escola Politécnica da Universidade de São Paulo. 221p. + apêndices. São Paulo.

(39) IBGE - Instituto Brasileiro de Geografia e Estatística (1997). Anuário Estatístico do Brasil 1996 (cd-rom).

(40) Industry Directions (2000). The Next Wave of Supply Chain Advantage: Collaborative Planning, Forecasting and Replenishment. CPFR Survey Findings \& Analysis.

(41) Jayakrishnan, R.; Mahmassani, H.S. \& Liu, Y.H. (1994). An evaluation tool for advanced traffic information and management systems in urban networks. Transportation Research (Part C), 2(3), 129-147. 
(42) Kahl, S.J. (1998). What's the "value" of supply chain software? Supply chain review.

(43) Karolefsky, J. (2001). Collaboration Across the Supply Chain. EUA.

(44) Lambert, D.M.; Stock, J.R. \& Ellram, L.M. (1998). Fundamentals of Logistic Management. Irwin McGraw-Hill, Boston, EUA.

(45) Lambert, D.M. \& Stock, J.R. (1993). Strategic Logistics Management. Irwin McGrawHill, Boston, EUA.

(46) Laporte, G.; Gendreau, M.; Potvin, J.Y. \& Semet, F. (2000). Classical and modern heuristic for the vehicle routing problem. International Transactions in Operational Research, 7, 285-300.

(47) Leclerc, F. \& Potvin, J.Y. (1997). Genetic Algorithms for Vehicle Dispatching. International Transactions in Operational Research, 4(5-6), 391-400, Elsevier Science, EUA.

(48) Levi, D.S. \& Kaminsky, P. (2000). Designing and Managing the Supply Chain. S-Levi/ Irwin McGraw-Hill, EUA.

(49) Lin, C.C. (2001). The Freight routing problem of time-definite freight delivery common carriers. Transportation Research (Part B), 35(6), 525-547, Elsevier Science, EUA.

(50) Mahmassani, H.S. \& Liu, Y.H. (1999). Dynamics of commuting decision behaviour under advanced traveller information systems. Transportation Research (Part C), 7(2-3), 91-107, Elsevier Science.

(51) Novaes, A.G. (2001). Logística e Gerenciamento da Cadeia de Distribuição. Editora Campus.

(52) Periódico: "Os Maggi continuam investindo na soja" (2003). O Estado de São Paulo, 8 de janeiro de 2003.

(53) Periódico: “A Vale mostra suas armas” (2003). Revista Fluxo, 01/01/2003. Divulgação através do site oficial da CVRD <www.cvrd.com.br>.

(54) Periódico: “Irreversível Globalização" (1999). ISTO É, nº 1550, 16 de junho de 1999.

(55) Periódico: "Eleito para celeiro do mundo" (2002). Gazeta Mercantil, jornalista Ariverson Feltrin, setembro de 2002.

(56) Periódico: "Latinos superam EUA no transporte de soja" (2001). O Estado de São Paulo, 16 de julho de 2001.

(57) Potvin, J.Y.; Duhamel, C. \& Guerti, F. (1994). A Genetic Algorithm for Vehicle Routing With backhauling. Centre Research Transportation of Montreal, Canadá.

(58) Potvin, J.Y.; Rousseau, J.M. \& Duhamel, C. (1994). A Tabu Search Heuristic for the Vehicle Routing Problem with backhauls and time Windows. CRT Montreal, University de Montreal, Canadá.

(59) Potvin, J.Y.; Sun, T. \& Thangiah, S.R. (1996). Heuristics Approaches to Vehicle Routing With Backhauls and Time Windows. Computers \& Operations Research, 23(11), 1043-1057, Elsevier Science, EUA. 
(60) Powell, W.B. \& Carvalho, T.A. (1997). Dynamic Control of Multi-commodity Fleet Management Problems. European Journal of Operation Research, 98(3), 522-541, Elsevier Science.

(61) Psarafits, H.N. (1995). Dynamic vehicle routing: Status and Prospects. National Technical Annals of Operations Research, University of Athens, Greece.

(62) Revista: e-Manager (2002). pgs. 22-24 Hugo Yoshizaki, "A nova face da Logística"; pgs. 28-31 Daniel Loneeff, "Pré-à-porter, semipronta e sob medida", jan/fev 2002.

(63) Santoro, M.C. (1999). Notas de Aula. Escola Politécnica da Universidade de São Paulo, Departamento de Produção, São Paulo, Brasil.

(64) Séguin, R.; Potvin, J.Y.; Crainic, T.G. \& Marcotte, P. (1997). Real Time Decision Problems: an Operational Research Perspective. Centre de Recherche sur les Transports. Journal of the Operation Research Society. Montreal University, Canadá.

(65) Solomon, M.M. (1987). Algorithms for the Vehicle Routing and Scheduling Problems with time Window Constraints. Operations Research, 35(2), 254-265, EUA.

(66) Sutherland, J. (2002). Collaborative Transportation: The road to supply chain improvement. EUA.

(67) Tacla, D. (1999). Estudo para Otimização de Rotas no Transporte Rodoviário de cargas granelizadas na Indústria Química. Dissertação de Mestrado. Escola Politécnica da Universidade de São Paulo, Brasil.

(68) Teodorovic, D. (1999). Fuzzy logic systems for transportation engineering: the state of the art. Transportation Research (Part A), 33(5), 337-364, Elsevier Science.

(69) Toth, P. \& Vigo, D. (1999). A heuristic algorithm for the symmetric and asymmetric vehicle routing problems with backhaul. European Journal of Operation Research, 113(3), 528-543, Elsevier Science.

(70) Wiley, John (1997). Managing Innovation. Reino Unido.

(71) Winston, W.L. (1994). Operations Research - Application and Algorithms. $3^{\text {a }}$ edição, Duxbury Press, EUA.

(72) Xinlian, X.; Tengfei, W. \& Daisong, C. (2000). A Dynamic Model and Algorithm for the Fleet Planning. Maritime Policy \& Management, 27(1), 53-63.

(73) Yoshizaki, H.T.Y. (1996). Planejamento e Projeto de Bases de Modelos Quantitativos de Auxílio à Decisão. Tese de Doutorado. Escola Politécnica da Universidade de São Paulo, Brasil. 